Piotr Prósinowski

https://doi.org.10.26881/ae.2018.15.10

ORCID: PP 0000-0002-0725-3065

Uniwersytet Gdański

piotr.games.research@gmail.com

Piotr Krzywdziński

ORCID: PK 0000-0002-5547-1294

Uniwersytet Gdański

krzywdzinski.piotr@gmail.com

\title{
Cyfrowe obrazy miłości: o grach wideo w kontekście miłości i bliskości
}

\section{Wprowadzenie}

Niniejszy tekst jest krytycznym sprawozdaniem z realizowanego przez nas projektu „Pedagogika kultury a «cyfrowa romantyczność» - badanie koncepcji romansów oraz seksualności w grach wideo w kontekście emocjonalnych potrzeb graczy, ich działań twórczych oraz wrażliwości społecznej”. Projekt realizowano w latach 2017-2018, chociaż prace koncepcyjne oraz zbieranie materiałów odbywało się jeszcze przed oficjalnym rozpoczęciem projektu, w roku 2016. Zwieńczeniem prac jest publikacja Cyfrowa miłość. Romanse w grach wideo wydana przez wydawnictwo Libron w drugiej połowie 2018 roku.

W ramach projektu mieliśmy do czynienia z połączeniem dwóch istotnych tematów, które wraz z rozwojem cywilizacyjnym zderzyły się, poszerzając tym samych sposób ich społecznego postrzegania i wprowadzając nowe ujęcia w toczące się od lat dyskursy. Pierwszym z tematów jest miłość - zagadnienie, które bez obaw można uznać za jedno z ważniejszych w kontekście istnienia człowieka i dość dobrze opracowane na gruncie różnych nauk - socjologii, pedagogiki, psychologii czy filozofii. Drugim zagadnieniem zaś jest szeroko rozumiana rozrywka elektroniczna, która stanowi temat stosunkowo młody. Mamy tu przede wszystkim na myśli gry wideo. Jako relatywnie nowe medium, gry ulegają ciągłym przemianom i transformacjom, na gruncie badawczym z kolei nadal zdają się przedmiotem przede wszystkim studiów eksploracyjnych, gdzie skonkretyzowana wiedza dopiero krystalizuje się w formy, które w przyszłości będą stanowić elementy spójnych, szerokich teorii 
naukowych. Dzięki tym eksploracjom medium to zaczyna być dostrzegane także w kontekście nauki, socjalizacji, wychowania, zdrowia, polityki czy sztuki.

Nadmieńmy, że temat relacji międzyludzkich zakorzenionych w nowych środkach przekazu również stanowi dziś istotny przedmiot badań i dyskusji. Upowszechnienie dostępu do Internetu wpłynęło znacząco na sposoby, w jakie ludzie wchodzą we wzajemne relacje, jak podtrzymują ze sobą kontakt lub budują mniej lub bardziej trwałe związki. Gry wideo często rozpatrywane są w tym kontekście jako jeden z kanałów komunikacyjnych. Te, które pozwalają na jednoczesną rozgrywkę wielu graczy, mogą być postrzegane jako nowa forma wchodzenia $w$ interakcje z drugą osobą - czy to za pośrednictwem tekstu, głosu czy różnego rodzaju symboli i gestów. W tym kontekście gry łatwo mogą być zredukowane do roli skrzynki mailowej, chatu lub sieciowego komunikatora tekstowego. W ten sposób często pomijana jest forma samej gry jako interaktywnego środowiska, które posiada własną, unikalną charakterystykę. Wynikiem tego jest rozpatrywanie szeroko pojętych wątków romantycznych w grach jako czegoś, co może wystąpić pomiędzy dwoma ludzkimi graczami, z pominięciem postaci niezależnych, kierowanych przez komputer, a stanowiących integralną część świata przedstawionego konkretnej gry. O doznawaniu emocji i uczuć w kontekście gier można mówić bowiem zarówno w odniesieniu do drugiego człowieka z którym gramy, jak i względem wydarzeń i osób budujących cyfrowe uniwersum rozgrywki.

Zdecydowaliśmy się zatem przenieść punkt ciężkości z relacji człowiek-człowiek na relację człowiek-maszyna. Analizowaliśmy sposoby, w jakie gracz za pośrednictwem swojego awatara wchodzi w relacje z postaciami niezależnymi (NPC), metody, których używają twórcy gier do oddawania relacji o charakterze romantycznym, oraz odbiór tego typu treści przez samych graczy. Ze względu na różnorodność form ludzkiej ekspresji o romantyczności, miłości i bliskości będziemy mówić zarówno w kontekście ekspresji fizycznej, jak i tej opierającej się na wewnętrznych potrzebach i pragnieniach.

Stare i nowe - relacje pomiędzy grami wideo a doświadczeniami romantycznymi

Miłość jest terminem na tyle szerokim i pojemnym, że można nim objąć wiele różnych zjawisk oraz postaw - nie tylko wobec ludzi, ale także zwierząt, przedmiotów nieożywionych, zjawisk, zachowań bądź bytów metafizycznych. Można więc kochać psy, piesze wędrówki po górach, Boga (lub bogów) oraz całe spektrum różnych innych rzeczy, osób i zjawisk. Jest też uczuciem, które można wyrazić na wiele sposobów. W psychologicznym ujęciu miłości pomiędzy ludźmi przypisuje się specyficzne elementy, takie jak zaangażowanie emocjonalne, intymność łączącą strony tej relacji, a także namiętność, charakteryzującą się erotyzmem, zainteresowaniem bliskością fizyczną (Wojciszke 1994: 7-18). 
Zwykło się też przyjmować, że miłość jako zjawisko kulturowe jest powszechne i występuje pośród ludzi jako coś uniwersalnego, niezależnego od położenia geograficznego, momentu historycznego czy innych uwarunkowań społecznych, ekonomicznych, politycznych. W myśleniu potocznym w miłości często upatruje się rodzaju ogólnoludzkiego powszechnika. Czegoś, co łączy wszystkie kręgi cywilizacyjne we wspólnej idei międzyludzkiej bliskości. Badania wydają się jednak wskazywać na coś innego. Miłość jawi się jako forma społecznie konstruowanej praktyki, dla której trudno znaleźć jedną, wspólną definicję, a bywa też oceniana w rozmaity sposób. Może być więc postrzegana bądź jako doniosłe uczucie, o zgoła metafizycznym podłożu, oparte na duchowej bliskości, bądź jako rodzaj choroby, zauroczenia czy wręcz zaślepienia motywowanego fizycznym pożądaniem (Dion, Dion 1996: 5-7). $\mathrm{W}$ miłości jedni widzieć będą jedynie biologię, inni natomiast pierwiastek boski.

Punktem wyjścia dla wszelkich dalszych rozważań jest tutaj stwierdzenie, że miłość - jakkolwiek pojmowana - jest zjawiskiem z gruntu kulturowym, silnie kontekstualnym. W rezultacie „kochać” w zależności od miejsca i czasu może odnosić się do zupełnie innego zestawu postaw, pozytywnych czy też negatywnych. Tym bardziej że we współczesnej kulturze popularnej dominujący wydaje się obraz miłości romantycznej, zawierający w sobie liczne, wewnętrznie sprzeczne elementy. Nic więc dziwnego, że uczucie to jest przedstawiane z jednej strony jako silnie transcendentne, łączące kochanków duchowo, oparte na bliskości, wzajemnym zaufaniu i dopełnianiu się do niejako wyższej formy egzystencji, z drugiej zaś często jest portretowana nie jako powolny proces, ale rodzaj doznania granicznego - pojawiającego się spontanicznie, łączącego ludzi nagle, „od pierwszego wejrzenia”, jak gdyby za dotknięciem czarodziejskiej różdżki lub za pośrednictwem nieodwołalnego wyroku losu.

Sam sposób mówienia o miłości może być bardzo zróżnicowany - a dobrane pojęcia zależne od kontekstu, w którym w danym momencie się poruszamy. Słowo „miłość” będzie nie tylko rozumiane jedynie przez ludzi znających język polski, ale będzie także kojarzyć się Polakom z konkretnymi konstrukcjami kulturowymi, mocno rozpoznawalnymi na terenie kraju. Angielskie „love” będzie rozumiane przez tych, którzy znają angielski. Co więcej, będzie to słowo kojarzone z popularnymi piosenkami o miłości, wykonywanymi przez różne światowej sławy gwiazdy. Natomiast ciąg 01101100011011110111011001100101 nie tylko wyda się większości ludzi przypadkowym łańcuchem cyfr. Będzie on dla nich znaczeniowym bełkotem. Jednocześnie urządzenia cyfrowe rozpoznają to słowo jako właśnie angielskie „love” zapisane w kodzie binarnym. Forma przedstawianego słowa to nie tylko skojarzenia i znaczenia (pełne semantycznych niuansów), ale również rozumienie - także to czysto formalne.

Relacja pomiędzy grami wideo a sposobem przedstawiania $\mathrm{w}$ nich treści romantycznych wykracza jednak poza obszar samego tylko, wąsko pojętego języka. Gry komputerowe są przede wszystkim multimedialnymi wytworami kultury. Łączą w sobie tekst pisany, język mówiony, rozmaite efekty dźwiękowe oraz obraz. W każdej produkcji relacje pomiędzy tymi elementami mogą być bardziej 
zróżnicowane, zaś samo komunikowanie treści użytkownikowi (graczowi) może być bardziej lub mniej zależne od poszczególnych czynników. Można zaryzykować twierdzenie, że wraz z rozwojem medium wzrasta komunikacyjna rola aspektów wizualnych. Pozwala na to rozwój technologiczny, który stwarza twórcom gier (deweloperom) coraz szersze możliwości operowania bardziej realistycznymi obrazami. Tendencja ta jednak nie jest tak uniwersalna, jak można by sądzić. Poszczególne produkcje, w zależności od artystycznej wizji ich autorów (oraz dostępnych środków - na przykład finansowych), mogą posługiwać się mniej fotorealistyczną warstwą graficzną lub wręcz celowo odrzucać realizm na rzecz innych stylistyk, mających budzić określone skojarzenia. Chyba najbardziej jaskrawymi przykładami takich gier są te tworzone w stylistyce tzw. pixel artu, które swym wyglądem mają przypominać produkcje tworzone wiele lat temu. Decyzja taka może być motywowana sentymentem do określonych gier sprzed lat bądź też zwykłą sympatią do tego rodzaju przestawień graficznych. Innym przykładem może być stosowanie w grafice stylistyki komiksowej, osiągane przez renderowanie obrazu w technice cel-shading. Wówczas grafika w grze jest bardziej kontrastująca, wyraźnie odróżniając się od fotograficznego realizmu. Innymi słowy, w produkcji gier wideo nie chodzi jedynie o tworzenie coraz bardziej realistycznych odwzorowań, lecz także o eksperymenty graficznie i zapewnianie czegoś, co można nazwać wizualnymi kontekstami.

Nie będziemy wdawać się tu w zbędne szczegółowe rozpatrywanie stylistyk, których można wyróżnić na tyle wiele, by stworzyć osobną publikację na ten temat. Zaznaczymy tylko, że przyjęcie przez dewelopera określonej artystycznej konwencji w grze będzie miało bezpośredni wpływ na sposób przedstawiania graczowi treści romantycznych, a co za tym idzie - na rodzaje udostępnionych mu narzędzi umożliwiających interakcje $\mathrm{z}$ bohaterami niezależnymi, z którymi może nawiązać bliższe relacje.

\section{Komunikacja wizualna i komunikacja tekstowa}

Aby możliwe było nawiązanie jakiejkolwiek relacji pomiędzy awatarem gracza a bohaterem niezależnym, niezbędna jest oczywiście forma komunikacji. Akt komunikacji pomiędzy awatarem a NPC jest czymś zupełnie innym niż na przykład rozmowa dwóch osób. Możliwości są tutaj dwie, zależne bezpośrednio od charakterystyki rozgrywki w konkretnej produkcji. Jeśli gracz w świecie gry posiada własnego awatara, to jest rodzaj swojej cyfrowej manifestacji w świecie przedstawionym, $\mathrm{z}$ reguły wszelkie interakcje będą $\mathrm{w}$ nim zapośredniczone. $\mathrm{Z}$ drugiej strony istnieją przecież gry zawierające treści romantyczne lub po prostu związane $\mathrm{z}$ budowaniem relacji, $\mathrm{w}$ których gracz nie jest reprezentowany przez własną postać. Przykładem mogą być gry strategiczne, w których gracz najczęściej jest raczej bezosobową siłą wpływającą na zachowania postaci niezależnych, bez konkretnej formy (postaci) zakorzeniającej go w uniwersum gry. 
Jeśli gracz ma awatara, za jego pośrednictwem wchodzi w interakcje $\mathrm{z}$ innymi postaciami. Najczęściej dzieje się to poprzez rozpoczynanie sekwencji dialogowych, pozwalających na prowadzenie rozmów z postaciami zamieszkującymi świat gry. Alternatywnie - poprzez podejmowanie działań niosących za sobą określone znaczenia. Tak jest na przykład w serii gier Fable, w której większość interakcji z bohaterami niezależnymi odbywa się na płaszczyźnie gestów. Awatar gracza nie „mówi” bezpośrednio, lecz raczej wykonuje określone akcje wyrażające jego intencje. Może więc przytulić kogoś, pomachać doń przyjaźnie, zrobić groźną minę lub wykonać wulgarny gest. Komunikacja słowna jest tam na tyle ograniczona, że niekiedy można zapomnieć o jej istnieniu. Dodatkowo gra informuje gracza o reakcjach bohaterów niezależnych przez serie znaków graficznych mających oddawać emocje otoczenia. Komunikacja przez posługiwanie się powszechnie rozumianymi znakami czyni grę bardziej intuicyjną i prostszą. Usuwa przy tym przynajmniej częściowo barierę językową oraz pozwala graczowi na zachowanie immersji, unikając wytrącania go z naturalnego rytmu rozgrywki

Oczywiście forma komunikacji tekstowo-wizualnej będzie niemalże całkowicie uzależniona od designu danej produkcji, silnika, na którym jest budowana, pomysłu na samą historię oraz to, jak wpisują się w nią możliwości budowania relacji. Fable stanowi tutaj tylko przykład jednego z możliwych sposobów podejścia do tego zagadnienia. Dla pewnego kontrastu można zauważyć, że relacje w Baldur's Gate 2: Cienie Amn będą przedstawione niemalże całkowicie tekstowo. W trakcie gry uniwersum „zamiera”, podczas gdy dialogi i opcje odpowiedzi przedstawione będą w tzw. oknie dialogowym. Częste są także kombinacje, gdzie postacie będą wykorzystywać zarówno gesty, jak i tekst (w różnych proporcjach) - na przykład w serii Dragon Age. Kwestia obrazowania i ubierania romansu w słowa będzie wyglądać jeszcze inaczej w grach z serii visual novel - na przykład w Katawa Shoujo czy Nicole. We wszystkich tych grach tekst i obraz korespondują z ograniczeniami na poziomie tworzenia postaci.

O formach przedstawiania romansów, sposobach na angażowanie gracza, przedziałach swobody w romansowaniu i prezentowaniu emocji można pisać wiele, co jedynie potwierdza mnogość ludzkich potrzeb wyrazu i prezentowania absorbującej bliskości. Podczas realizacji projektu przeanalizowaliśmy ponad pięćdziesiąt gier wideo zawierających romanse o zróżnicowanych konstrukcjach. Jedne, konserwatywne w swoich przekazach, inne natomiast inkluzywne w kontekście orientacji seksualnej i nie tylko. To każe myśleć, że romanse w grach wideo są tak samo zróżnicowane jak ludzkie pojmowanie bliskości, miłości oraz relacji romantycznej. Niektóre stosowane $\mathrm{w}$ grach rozwiązania prezentacji treści romantycznych kontrastują ze sobą na tyle, że zdają się nie do pogodzenia w ramach jednej produkcji. Nie będzie niczym odkrywczym stwierdzenie, że każdy z nas ma inne oczekiwania względem swoich życiowych partnerów bądź partnerek. Każdy inaczej wyobraża sobie to, jaki powinien być związek. Nie każdy jednak wie, że gry wideo doskonale obrazują różnorodność pojmowania tego elementu życia społecznego. Tak jak zróżnicowane jest to, co intryguje poszczególnych ludzi, podnieca bądź współgra 
$\mathrm{z}$ „wyznawaną” estetyką, tak i niejednorodne jest odbicie miłości na ekranie monitora. W konsekwencji trudno mówić o jednym, ogólnym komunikacie dotyczącym miłości, płciowości czy cielesności. Tak duże zróżnicowanie ma konsekwencje dla odbiorców. Chociaż większość graczy popiera obecność romansów w grach wideo, ponieważ wzbogacają według nich rozgrywkę, to jednak znaczna ich część ma nieprzychylne zdanie o konkretnych grach, które je zawierają. To właśnie dlatego, że prezentowane (zarówno wizualnie, jak i tekstowo) przez nie obrazy miłości nie odpowiadają uznawanym przez tych konkretnych graczy ideom miłości. Tak więc gracze o konserwatywnych poglądach nierzadko wskazują produkcje takie jak Dragon Age: Inkwizycja jako zaprzeczenie tego, jak romanse w grach powinny wyglądać (często $\mathrm{z}$ powodu bardzo inkluzywnego podejścia dewelopera gry w tym przypadku BioWare). Inni natomiast będą nazywać się fanami tejże gry właśnie dzięki temu, co znienawidzone przez pierwszą grupę. Także seksualność ludzka staje się swojego rodzaju ogniskiem sporu, toczącego się wokół konkretnej produkcji, co w gruncie rzeczy czyni z romansów jeszcze ważniejszą kwestię.

Trudno się dziwić, że romanse w grach potrafią budzić skrajne uczucia i emocje. $Z$ jednej strony nienawiść, obrzydzenie, $z$ drugiej uwielbienie, podniecenie. We wzbudzaniu tychże reakcji niewątpliwie uczestniczą różne elementy wchodzące w synergię i wspólnie budujące romans w danej grze: wizualne, dźwiękowe, tekstowe.

Jak zauważa Magdalena Cielecka (2014), erotyka i seksualność w grach wideo nie są czymś nowym. Ciekawe natomiast jest to, że chociaż romanse w grach wideo pojawiały się już kilkanaście lat temu, to wciąż uważane są za temat drażliwy. Na podstawie przeprowadzonych przez nas badań można wysnuć wniosek, że ma to związek z sytuacją polityczną - ukazywanie miłości samo w sobie jest polityczne. Miłość i seksualność bowiem dotyczy także takich kwestii jak to, co akceptowalne, a co nie. Tego, co obyczajne, i tego, co nieobyczajne. Szczególnym względem będzie tu darzone wizualne ukazywanie miłości, a w końcu i ono istnieje w grach. Zwłaszcza jeśli produkt skierowany jest do konkretnej grupy. Przykładem może tu być subkultura furry, czyli wiążąca się fanami antropomorficznych postaci zwierzęcych (więcej i bardziej szczegółowo o subkulturze można przeczytać w: Nyareon 2015: 5-11 lub Strike 2017: 1-12). Gry z gatunku visual novel skierowane do tej konkretnej subkultury - na przykład Nekojishi - nie będą znane szerszej publiczności, a osoby spoza docelowej grupy odbiorców, które na nią trafią, mogą uznać ją za niezrozumiałą, dziwną, a nawet niestosowną. Natomiast osoby z fandomu furry ze względu na swoją tożsamość uznają taką produkcję za ciekawą, odpowiadającą ich potrzebom, a nawet na swój sposób emancypującą.

\section{Gracze o romansach}

W trakcie projektu nie ograniczyliśmy się jedynie do analizy gier, które uwzględniają romanse. Przeprowadziliśmy także 31 wywiadów - 20 z graczami, którym romanse $\mathrm{w}$ grach wideo nie są obce, oraz $11 \mathrm{z}$ modderami (autorami nieoficjalnych, fanowskich dodatków do gier), którzy postanowili stworzyć dodatek (lub 
dodatki) o charakterze romansowym. W rozmowach tych pragnęliśmy dowiedzieć się więcej na temat: a) opinii o romansach w grach i ich odbiorze wśród graczy; b) motywacji do tworzenia takiego typu dodatków i wykorzystywanych strategii twórczych w przypadku modderów. Dobór grupy był celowy, a próbę zbudowano z przedstawicieli różnych krajów, orientacji seksualnych, płci oraz stanu cywilnego. Wywiady analizowano metodą teorii ugruntowanej, przy wsparciu oprogramowania komputerowego Weft QDA.

W opiniach naszych respondentów było można było dostrzec kilka kluczowych elementów wskazujących na znaczenie treści romantycznych rozpoznawanych przez nich w grach.

Podstawową i chyba najbardziej akcentowaną w wypowiedziach kategorią była waga obrazów miłości oraz angażujących relacji dla pogłębiania immersji. Przez immersję rozumiemy tutaj poczucie zanurzenia $\mathrm{w}$ interaktywnym świecie przedstawionym gry (Filiciak 2006: 62). Według graczy możliwość nawiązania znaczącej relacji z postaciami niezależnymi była istotnym składnikiem wiarygodności uniwersum gry. Dzięki niej przedstawione miejsca, ludzie czy wydarzenia nie tylko stają się bardziej realistyczne - sama rozgrywka zdaje się bliższa prawdziwemu życiu. Miłość była rozpoznawana w tym kontekście jako jeden z kluczowych elementów ludzkiej egzystencji. Nie tylko relacje romantyczne, ale wszelkie możliwości nawiązywania pogłębionych więzi z bohaterami niezależnymi świata gry są rozpatrywane jako pozytywna wartość. Często pojawiały się tutaj kategorie takie jak „zaangażowanie”, „zainteresowanie”, czy „troska”. Postać, z którą gracz może wejść w emocjonalny związek, ma dla odbiorcy znaczenie, sama relacja zaś staje się elementem motywującym do dalszej rozgrywki. Wirtualne wydarzenia przestają być tylko historią oglądaną z boku, bez emocjonalnego zaangażowania. Przez nadanie jej bardziej ludzkiego charakteru, kolejne przygody, pozytywne czy negatywne, nabierają emocjonalnej wagi i na dłużej zapadają w pamięć.

$\mathrm{Z}$ immersją jest również powiązany aspekt swoistego dopasowania się świata do gracza. Jeśli gra pozostawia odbiorcy wybór co do tego z kim, jakiego rodzaju i jak będzie budował emocjonalne relacje, sam jej świat staje się fabularnie bardziej interaktywny. Z punktu widzenia gracza opowiadana historia również nabiera bardziej osobistego charakteru. Możliwość lepszego poznania niektórych postaci niezależnych, zaprzyjaźnienia się z częścią z nich lub - wprost przeciwnie - zantagonizowania ich względem siebie sprawia, że zanika tak problematyczne w grach poczucie liniowości. Podejmowane decyzje, naznaczone emocjonalnym i uczuciowym zaangażowaniem, stają się czymś unikatowym dla każdego kolejnego podejścia do gry. Sprawia to, że dwie osoby obcujące $\mathrm{z}$ tą samą produkcją mogą mieć zupełnie inne wrażenia, doświadczenia czy wspomnienia z nią związane.

Warto $\mathrm{w}$ tym miejscu nadmienić, że dostosowanie świata przedstawionego poprzez budowane relacje miało bardzo duże znaczenie dla modderów oraz dla graczy. Kilkakrotnie pojawiły się opinie, że właśnie dzięki temu aspektowi gry stały się ważną formą ekspresji siebie, swoich potrzeb, pragnień czy marzeń, a szerzej - sposobem zamanifestowania własnej tożsamości. Szczególną uwagę na tę 
stronę zagadnienia zwracały osoby, dla których istotna była kwestia reprezentowania w grach przedstawicieli mniejszości seksualnych. Pojawiały się tu głosy, że świat wirtualny stanowił istotną przestrzeń eksplorowania własnej seksualności. $\mathrm{W}$ przypadku gier $\mathrm{z}$ bardzo rozbudowanym wątkiem romantycznym można mówić o swoistym laboratorium, w ramach którego gracz ma możliwość w kontrolowany sposób poznawać samego siebie. Jest to środowisko z jednej strony bezpieczne, niezobowiązujące ostatecznie do niczego, gdzie decyzje nie są z reguły nieodwołalne - ale jednocześnie gra stanowi przestrzeń, w której również można budować zaangażowanie emocjonalne i uczuciowe.

Co ciekawe, to samo, co buduje potencjał gier wideo umożliwiający eksplorację własnej tożsamości, przez niektórych graczy postrzegane jest jako element przeciwstawny do świata rzeczywistego - gra jest miejscem bezpiecznym, w którym coming out przestaje być ryzykowny. To może stanowić trening pracy nad własną tożsamością jako coś odmiennego od tego w świecie wirtualnym, a reakcje postaci z gier wcale nie muszą odpowiadać tym, które pojawiłyby się w świecie realnym. Jednakże nie umniejsza to możliwości indywidualnej pracy nad akceptacją. W tym sensie monitor komputera staje się zwierciadłem, przed którym gracz może przyznać się przed samym sobą do swoich uczuć, pragnień i przemyśleń, co także jest gigantycznym potencjałem.

Poza wymienionymi kategoriami wyłoniły się także inne kwestie, takie jak: realne reakcje na wirtualną treść (śmiech, łzy) sugerujące potencjał gier do stymulowania przeżywania rożnych uczuć i emocji; polityczność gier, czyli ich zakorzenienie w naszych codziennych dyskursach i kontekstach polityczno-kulturowych; (nie)zbędność romansów, czyli ich korespondencja z potrzebami jednostek, choć wydają się obojętne innym, mniej nastawionym na ten element rozgrywki graczom. Mnogość kategorii i przemyśleń jeszcze bardziej podkreśla kompleksowość tematu romansów w grach wideo i wielość ich konotacji z różnymi obszarami życia badanych.

\section{Romanse a socjalizacja i wychowanie}

Myśląc o grach wideo i pedagogice, należy odpowiedzieć na pytanie o relację, która między nimi zachodzi. Gry wideo jako element kultury popularnej, jako znaczący rodzaj tekstów kultury wchodzą $\mathrm{w}$ istotny rezonans $\mathrm{z}$ naszą codziennością, a więc także z naszą socjalizacją i wychowaniem (rozumianym w sposób szeroki, nieograniczający się jedynie do oddziaływań rodziców czy szkoły). Wiele osób powiedziałoby, że gry wideo to „tylko fikcja”. Błąd - to aż fikcja. Pomimo swojej niesławy i rozumienia jako czegoś stojącego w opozycji to prawdy (Neubauer-Vasquez 2011: 65) to fikcja tworzy naszą codzienność. Zauważają to chociażby Tomasz Szkudlarek i Zbyszko Melosik (2010: 97): „Jesteśmy więc tworzeni przez fikcje. Opowieści przekazywane ustnie, teksty literackie, gazety i telewizja wszystkie te narracje tworzą świat naszego doświadczenia niemal nierozróżnialny od świata «realnego»". 
Oczywiście z czystym sumieniem do wymienionych rodzajów mediów można dopisać gry wideo czy Internet. Fikcja jest częścią naszego codziennego życia. To także w niej się wychowujemy i to w niej wrastamy w kulturę, uczymy się odczytywania otaczającego nas świata i jego symboli. Romana Miller dostrzega również, że przez fikcję artystyczną (a do takiej można zaliczyć gry wideo, myśląc o nich w kategorii synergii obrazów, tekstu, muzyki itd.) dochodzi do komunikacji i przyjmowania kultury zaoferowanej przez dane dzieło (Miller 1977: 53-58). Co więcej, nie dotyczy to tylko dzieci czy młodzieży, a człowieka w jakimkolwiek wieku. Zwłaszcza jeśli myślimy o socjalizacji i o wychowaniu jako procesach całożyciowych, niekończących się.

Na podstawie przeprowadzonych wywiadów możemy powiedzieć, że - przynajmniej w doświadczeniach graczy oraz twórców dodatków - romanse w grach na swój sposób mogą wychowywać do intymności z drugą osobą. Mogą opowiadać o budowaniu relacji z innymi ludźmi, trosce o ich stan, zainteresowaniu ich sprawami i problemami. Mogą też opowiadać o doznaniach fizycznych. Szaleństwem byłoby twierdzić, że wśród mnogości gier wszystkie przedstawiają jedną wizję i ideę romantycznej relacji, do której socjalizują swoich odbiorców. Jak każde inne medium, przedstawiają wiele zróżnicowanych perspektyw i podejść do relacji międzyludzkich. Tak samo jak Duma i uprzedzenie autorstwa Jane Austen nie będzie opowiadać o tej samej miłości co Zmierzch Stephenie Meyer czy Wyznania gejszy Arthura Goldena.

Gdy mówimy o grach wideo, musimy pamiętać, że jest to medium - pomimo relatywnie krótkiej historii - bardzo rozbudowane, w ramach którego odnajdziemy produkcje dotykające najrozmaitszych tematów, problemów i zagadnień. Nic więc dziwnego, że odnajdywane w nich portrety miłości i relacji międzyludzkich w ogólności różnie rozkładają akcenty pomiędzy tym wszystkim, co składa się na znaczącą relację. W niektórych pozycjach dużo większy nacisk położony może być na materialno-ekonomiczną stronę wspólnego życia. Przykładem tego jest bardzo dobrze rozpoznawana seria The Sims, w której międzyludzkie interakcje mają raczej zgeneralizowany charakter, nie ukazują szczegółowo dialogów, emocjonalnych problemów czy moralnych dylematów. Zamiast tego względnie trafnie ilustrują dynamikę indywidualnych potrzeb, rodzinnego zarządzania finansami czy problemu łączenia kariery zawodowej z życiem osobistym. Inne produkcje mogą z kolei abstrahować całkowicie od tych zagadnień, koncentrując się bardziej na doznaniach wewnętrznych, emocjach i uczuciach towarzyszących bliskości (tutaj można podać za przykład Fragments of Him dewelopera Sassybot lub dość niejednoznaczną, ale bazującą na zrozumieniu relację pomiędzy bohaterami Firewatch studia Campo Santo). Niemałe jest też grono gier, których dominantą jest na przykład życie erotyczne. W tym przypadku jako przykład można podać House Party autorstwa Eek! Games, czy w pewnym sensie także Sakura Spirit wyprodukowane przez Winged Cloud.

Podobnie jak mechaniki poszczególnych gier kładą nacisk na zróżnicowane aspekty związków, tak też sama miłość i partnerstwo w grze może pełnić odmienne 
funkcje w ogólnej konstrukcji uniwersum. Podczas gdy w niektórych grach stanowią one centralny wątek akcji i wiążą fabułę w jedną całość, w innych może to być element całkowicie poboczny, stanowiący jedynie uzupełnienie większej historii.

Projektowanie tego, jak ważne będą relacje romantyczne, jak doniosły będą miały wpływ na rozgrywkę i jakie ich aspekty zostaną w jej ramach uwzględnione, pozostaje zależne całkowicie od decyzji deweloperów konkretnej produkcji. Ta zwykle jest podyktowana wypadkową kilku czynników - takich jak tematyka gry, kluczowe mechaniki tworzące samo doświadczenie rozgrywki czy postrzegane przez twórców oczekiwania potencjalnych odbiorców. Ostateczna decyzja o doświadczeniu romansu należy jednak do gracza - czy sięgnie po daną produkcję, czy wejdzie w opcjonalny romans, czy może zdecyduje się na zupełnie inną rozgrywkę.

Można powiedzieć, że gry wychowują do doświadczania. Są zaplanowanymi konstruktami, które będą rozbudzać u gracza silne uczucia i emocje. Oferują historie o miłości, pożądaniu, bliskości cielesnej bądź duchowej. Treść gier różni się jednak od tego, co proponują inne media, bo już z definicji wymagają one aktywnego uczestnictwa w rozgrywce. Nie tylko więc opowiadają o nich, ale angażują użytkowników. Czynią z nich aktorów, którzy - jeśli tego właśnie zapragną - mogą wzruszyć się, podniecić... niekiedy przeżyć swoiste romantyczne katharsis.

\section{Myśli końcowe}

Tematyka romansów w grach wideo budzi obecnie silne emocje - na razie przede wszystkim wśród graczy. Niestety, dotychczasowe doświadczenia pokazywały, że szersza opinia publiczna interesowała się nimi przede wszystkim wówczas, gdy $\mathrm{w}$ mediach podnosiły się głosy oburzenia lub paniki. Nawet starsza literatura naukowa w tym zakresie zdawała się dość uboga i zwracała przede wszystkim uwagę na negatywne aspekty emocjonalnego zaangażowania w rozgrywkę lub też sprzeciwiała się nieodpowiednim - w mniemaniu niektórych - treściom, które pojawiały się w grach. W połączeniu pojęć „romans” i „gra wideo” wciąż pewnie wiele osób jest skłonnych wyobrażać sobie wulgarną pornografię, operowanie erotyzmem mające przyciągnąć uwagę odbiorców.

Niekiedy łatwo zapomnieć, że wraz z ewolucją gier wideo rozbudowaniu uległo nie tylko spektrum poruszanych przez nie problemów, ale także zmienił się stopień złożoności ich ukazywania. Podobnie jak w literaturze czy filmie, reprezentacje miłości, bliskości czy przyjaźni stają się coraz bardziej rozwinięte, angażujące i głębsze w swej wymowie. Jest to również związane z podnoszeniem się ogólnego poziomu debaty na temat gier i ich miejsca w kulturze współczesnej. Stają się też dzięki temu bardziej rozpoznawalne w ramach dyskursów politycznych. Same romanse - jak już wspomnieliśmy - będące przedmiotem licznych dyskusji wśród graczy, są tego doskonałym przykładem. Ich obecność w grach, 
a także reprezentacje rozmaitych mniejszości seksualnych powodują coraz liczniejsze kontrowersje i spory wśród odbiorców. Zdaje się to jednak naturalną konsekwencją rosnącej doniosłości i zwiększającego się wpływu gier na kształtowanie współczesnych nurtów kulturowych. Przez swą rozpoznawalność są identyfikowane jako istotne elementy dyskursów politycznych, a także procesów socjalizacyjnych. Nie jest więc niczym dziwnym, że wiele osób będzie oczekiwać od gier stanowczego ujawniania społecznej różnorodności. Inni natomiast - co zresztą często się dzieje - będą nawoływać do „odpolitycznienia” gier, powrotu do czasu wolności tego medium od tematów związanych z seksualnością, wizerunkami kobiet, mężczyzn, prawa, (nie)widzialności niektórych grup społecznych i temu podobnych. Problem polega jednak na tym, że gry to codzienność, a codzienność to zagadnienie z natury polityczne. Czym innym jest bowiem niż sposobem definiowania znaczeń oraz elementów dostrzegalnych i definiowalnych w praktyce życia. Tam więc, gdzie będą jakiekolwiek historie, postacie, idee, koncepcje, tam będzie też polityka.

Ostatecznie gry odpowiadają na ludzkie potrzeby. Jako element kultury symbolicznej dysponują potencjałem, by odpowiadać na potrzebę wyrażania miłości, bliskości, własnej tożsamości seksualnej. Nic więc dziwnego, że w ramach medium tematy te spotykają się z coraz bardziej wyrazistą reprezentacją. Trzeba jednak pamiętać, że gry nie są w tym względzie jednomyślnym medium, w ramach którego dominuje wyraźnie jeden tylko dyskurs. Zamiast tego mamy do czynienia $\mathrm{z}$ wielością i różnorodnością będącą bezpośrednią konsekwencją zróżnicowania wśród deweloperów oraz poszczególnych grup odbiorców. W ramach tej różnorodności gry - a właściwie prezentowane przez nie cyfrowe światy - pozostają istotnymi obszarami, w których człowiek może eksplorować i poznawać coraz lepiej siebie, budować własną tożsamość, a także uczyć się o świecie rzeczywistym i o tym, co ludzkie.

\section{Literatura}

Cielecka M., 2014, Brzemię interaktywności: erotyka i seksualność w grach komputerowych, "Replay. The Polish Journal of Game Studies", no. 1.

Dion K.K., Dion K.L., 1996, Cultural perspectives on romantic love, „Personal Relationships", no. 3.

Filiciak M., 2006, Wirtualny plac zabaw. Gry sieciowe i przemiany kultury współczesnej, Warszawa: Wydawnictwa Akademickie i Profesjonalne.

Melosik Z., Szkudlarek T., 2010, Kultura, tożsamość i edukacja - migotanie znaczeń, Kraków: Oficyna Wydawnicza Impuls.

Miller R., 1977, Wychowanie przez świat fikcyjny dla świata rzeczywistego we wczesnym dzieciństwie, [w:] Sztuka dla najmłodszych: teoria, recepcja, oddziaływanie, red. M. Tyszkowa, Warszawa-Poznań: PWN.

Neubauer-Vasquez S., 2011, Fikcja jako medium [w:] Wychowanie przez świat fikcyjny dla świata rzeczywistego, red. E. Rodziewicz, M. Cackowska, Gdańsk: Wydawnictwo Uniwersytetu Gdańskiego. 
Nyareon, 2015, The Furry Fandom [w:] Furries among us: essays on furries by the most prominent members of the fandom, ed. T. Howl, Nashville: Thurston Howl Publications.

Prósinowski P., Krzywdziński P., 2018, Cyfrowa miłość. Romanse w grach wideo, Kraków: Wydawnictwo Libron.

Strike J., 2017, Furry nation: the true story of America's most misunderstood subculture, Jersey City: Cleis Press.

Wojciszke B., 1994, Psychologia miłości: intymność, namiętność, zaangażowanie, Gdańsk: Gdańskie Wydawnictwo Psychologiczne.

\section{Ludografia}

BioWare Corporation, 2000, Baldur's Gate II: Cienie Amn, Interplay.

Campo Santo, 2016, Firewatch, Panic.

Dragon Age (seria):

BioWare Corporation, 2009, Dragon Age: Poczatek, Electronic Arts.

BioWare Corporation, 2011, Dragon Age II, Electronic Arts.

BioWare Corporation, 2014, Dragon Age: Inkwizycja, Electronic Arts.

Eek! Games, 2017, House Party, Eek! Games.

Fable (seria):

Lionhead Studios, 2004, Fable, Microsoft.

Lionhead Studios, 2005, Fable: The Lost Chapters, Microsoft.

Lionhead Studios, 2008, Fable II, Microsoft.

Lionhead Studios, 2010, Fable III, Microsoft.

Lionhead Studios, 2014, Fable Anniversary, Microsoft.

Four Leaf Studios, 2012, Katawa Shoujo, Four Leaf Studios.

Sassybot, 2016, Fragments of Him, Sassybot.

Team Nekojishi, 2017, Nekojishi, Orange Juice Dog.

The Sims (seria):

Maxis, 2000, The Sims, Electronic Arts.

Maxis, 2004, The Sims 2, Electronic Arts.

The Sims Studio, 2009, The Sims 3, Electronic Arts.

Maxis / The Sims Studio, 2014, The Sims 4, Electronic Arts.

Winged Cloud, 2014, Sakura Spirit, Winged Cloud.

Winter Wolves, 2013, Nicole, Winter Wolves.

\section{Inne materiały i narzędzia}

Weft QDA - oprogramowanie do analizy danych jakościowych, http://www.pressure.to/ qda/ [dostęp: 15.10.2018]. 


\section{Streszczenie}

Media często ukazują różne formy miłości i bliskości - zarówno tej fizycznej, jak i emocjonalnej. To między innymi one kształtują nasze ich postrzeganie oraz sposób, w jaki o nich mówimy. Gry wideo także uczestniczą w tym dyskursie, ukazując nam obrazy tej jednej z bardziej skomplikowanych ludzkich potrzeb, a poprzez swoją interaktywność oraz potencjał immersji pozwalają na swojego rodzaju ekspresję ludzkiej seksualności. Tekst ten jest zbiorem przemyśleń po realizacji projektu badawczego pt. „Pedagogika kultury a «cyfrowa romantyczność» - badanie koncepcji romansów oraz seksualności w grach wideo w kontekście emocjonalnych potrzeb graczy, ich działań twórczych oraz wrażliwości społecznej” (nr zadania: 538-7300-B640-17).

\section{Słowa kluczowe}

gry wideo, game studies, pedagogika, kultura, miłość, romantyczność

\section{Summary}

Digital pictures of love: on video games in the context of love and closeness

Media often present different forms of love and closeness - both physical and emotional. They, among other things, shape our perception of those matters and how we discuss them. Video games also participate in this discourse, showing us the images of these complex human needs, and through their interactivity and the potential of immersion, allow to express our sexuality. This text is in a way a collection of thoughts after the research project named „Pedagogy of culture and 'digital romance' - an analysis of the concept of romance and sexuality in video games in the context of the emotional needs of vide game players, their creative activities and social sensitivity" (Task number: 538-7300-B640-17), conducted at the University of Gdańsk.

\section{Keywords}

video games, game studies, pedagogy, culture, love, romanticism 